\title{
Digital Economy Development in Indonesia 2020
}

Ekonomi digital merupakan suatu bentuk kegiatan ekonomi yang menggunakan teknologi informasi dan komunikasi agar lebih aman dan efisien. Ekonomi digital ini merupakan transaksi terobosan yang baik, karena dapat menghindari kasus pencurian dan pembobolan dengan transaksi cashless. Setiap proses transaksi ekonomi digital akan lebih mudah, lancar, cepat dan aman. Ekonomi digital tidak dibatasi oleh jual beli barang, tetapi juga mencakup transaksi digital, dompet digital, pinjaman online, investasi dan lain-lain. Ekonomi digital di Indonesia akan terus berkembang pesat sehingga usaha mikro kecil menengah atau UMKM dapat memiliki peluang besar untuk memasarkan produk dan layanannya. Peningkatan transaksi pada e-commerce mencapai $40 \%$ pertahunnya, sedangkan jumlah pengguna internet di Indonesia mencapai 93,4 juta orang dan 71 juta pengguna smartphone. E-commerce dan ekonomi digital di masa mendatang akan mengalami perkembangan yang positif.

Undang-undang hak cipta memberikan dukungan bagi koperasi dan UMKM untuk bertransformasi. Ada lima transformasi yang diharapkan yaitu,

1. Transformasi bisnis informal hingga formal,

2. Transformasi digitalisasi,

3. Transformasi bisnis individu atau skala kecil ke ekonomi,

4. Transformasi berbasis teknologi,

5. Transformasi UMKM berbasis kawasan, komunitas, klaster dan rantai pasokan.

Di era pandemi covid-19, telah terbukti bahwa usaha mikro kecil menengah atau UMKM yang terhubung dengan platform digital mampu bertahan. Data penjualan menunjukkan pada kuartal kedua pengguna platform digital meningkat sebesar 26\%, dibandingkan dengan tahun lalu sementara yang tidak terhubung ke platform digital mengalami penurunan omset. Karena ekonomi digital membuat banyak perusahaan dan bisnis yang berkembang pesat sehingga membuat perusahaan dapat menyerap tenaga kerja dan mengurangi angka pengangguran. Di Indonesia ada banyak orang yang menggunakan ekonomi digital dalam proses jual beli barang di tempat pasar atau toko online, transportasi online juga tersedia melalui aplikasi ojek online atau pengiriman, sistem pembayaran melalui aplikasi online yang juga bisa untuk dompet digital atau menabung, dan investasi. 
Di era pandemi Covid-19 telah memaksa dan mendorong Indonesia untuk mempercepat transformasi digital. Pada tahun 2019 populasi pengguna internet telah mencapai 180 juta orang atau $67 \%$, dan populasi pengguna internet aktif telah mencapai 150 juta atau 56\%. Hingga 2020, ekonomi digital di Indonesia telah mencapai USD 44 miliar atau 633,88 triliun (kurs 14.406 per dolar AS) dan Compound Annual Growth Rate sekitar 44\% sejak 2015. Estimasi ekonomi digital Indonesia mencapai USD 124 miliar dengan Compound Annual Growth Rate sebesar 23\% sejak 2020. Meskipun pertumbuhan tahunan melambat, dengan penambahan USD 80 miliar pada 2020 dan 2025 setara USD 16 miliar per tahun. Ini mewakili 2,2 kali lebih tinggi dari nilai tambahan USD 36 miliar pada 2015 dan 2020 sebesar USD 7 miliar per tahun.

Perkembangan ekonomi digital pada tahun 2015 yaitu, nilai gross merchandise ecommerce adalah US 1,7 miliar; nilai gross merchandise dari perjalanan online sebesar US 5 miliar; nilai gross merchandise media online sebesar US 0,6 miliar; dan nilai gross merchandise transportasi online sebesar US 0,9 miliar. Kemudian mengalami perkembangan yang signifikan pada tahun 2019. Nilai gross merchandise e-commerce adalah US 21 miliar; nilai gross merchandise dari perjalanan online sebesar US 10 miliar; nilai gross merchandise media online sebesar US 4 miliar; dan nilai gross merchandise transportasi online sebesar US 6 miliar. Dan diperkirakan perkembangan ekonomi digital pada 2025 juga meningkat pesat dan signifikan. Nilai gross merchandise transaksi e-commerce US 82 miliar; nilai gross merchandise dari perjalanan online sebesar US 25 miliar; nilai gross merchandise media online sebesar US 9 miliar; dan barang kotor .

Sejak 2015 hingga 2025 perkembangan ekonomi digital di Indonesia sangat signifikan dan pesat karena semakin banyak masyarakat yang menggunakan transaksi digital untuk mempermudah transaksi. Nilai e-commerce dari 2015 hingga 2025 meningkat sebesar US 59,3 miliar, nilai perjalanan online meningkat sebesar US 10 miliar, nilai media online meningkat sebesar US 4,4 miliar, dan nilai transportasi online meningkat sebesar US 11,1 miliar. Perkembangan e-commerce dari 2015 hingga 2019 meningkat 88\% dan menurun pada 2025 sebesar 48\%. Perkembangan perjalanan online dari tahun 2015 hingga 2019 meningkat sebesar 19\% dan menurun pada 2025 sebesar 17\%. Perkembangan media online dari tahun 2015 hingga 2019 meningkat sebesar 56\% dan menurun pada 2025 sebesar 31\%. Perkembangan transportasi online pada 2015 hingga 2019 meningkat 57\% dan pada 2025 mengalami penurunan sebesar $34 \%$. 
Grafik Perkembangan Ekonomi Digital Indonesia 2015 hingga 2025
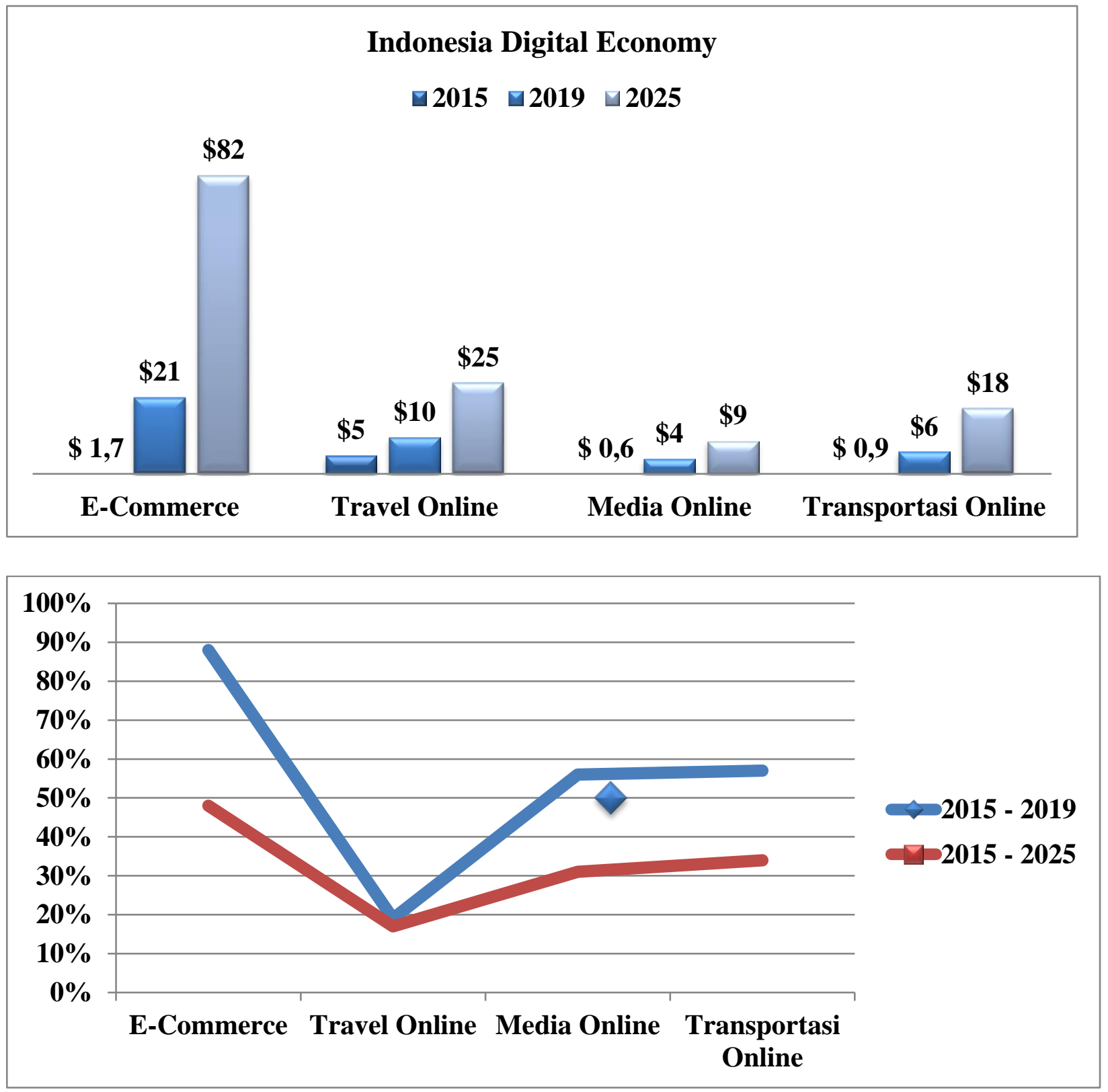

Di kawasan ASEAN, Indonesia memiliki nilai ekonomi digital sebesar US 27 juta pada 2018, dan akan tumbuh menjadi US 100 hingga US 150 juta pada 2025. Bahkan, pada periode 2015-2018, ekonomi digital di Indonesia memiliki pertumbuhan tercepat, mencapai 45\% . Dari sisi penetrasi internet, pengguna internet di Indonesia saat ini mencapai 171,17 juta pengguna dari total populasi sekitar 264 juta jiwa. Di Indonesia, ada banyak orang yang memanfaatkan ekonomi digital dalam transportasi online bukan hanya untuk perjalanan, tetapi pengiriman barang, pengiriman makanan atau minuman. Namun meskipun penggunaan transportasi online lebih unggul, transportasi online atau sejumlah perusahaan transportasi juga bekerja sama dengan perusahaan yang menyediakan layanan pembayaran 
online. Begitu banyak konsumen juga yang memanfaatkan promosi atau diskon atau gratis ongkir yang ada dalam sistem pembayaran. Sejak adanya pandemi Covid-1 ini, juga telah membawa banyak manfaat bagi e-commerce karena sekarang ada banyak konsumen yang beralih dari belanja offline menjadi belanja online. Dan banyak juga konsumen yang beralih dari pembayaran tunai atau cash menjadi non-tunai atau transaksi online.

Di era pandemi covid-19 ini membuat perkembangan yang sangat tinggi, pesat, dan signifikan bagi ekonomi digital khususnya di Indonesia. Indonesia merupakan kontributor tercepat dan juga kontributor terbesar bagi perkembangan ekonomi digital atau ekonomi berbasis internet di Asia Tenggara. Pesatnya ekonomi digital di Indonesia didominasi oleh daerah sekitarnya dengan total pengeluaran US 555 per kapita. Sedangkan untuk wilayah ter luar rata-rata total pengeluaran hanya mencapai US 103 per kapita. Sekarang pemerintah telah menerapkan pajak pertambahan nilai atau PPN digital bagi pelaku luar negeri, yang akan memungkinkan Negara Indonesia untuk meningkatkan pendapatan dari sektor potensial. 
Sumber:

https://qwords.com/blog/ekonomidigital/\#: :text=Ekonomi\%20digital\%20di\%20Indonesia\% 20terus,jumlah\%20ecommerce\%20yang\%20menjamur.\&text=Menilik\%20dari\%20data\%20 Ernst\%20\%26\%20Young,commerce\%20mencapai\%2040\%25\%20per\%20tahunnya.

https://www.liputan6.com/saham/read/4503947/potensi-ekonomi-digital-di-indonesia-meningkat https://databoks.katadata.co.id/datapublish/2019/10/04/inilah-potensi-ekonomi-digital-indonesia$\underline{2015-2025}$

https://katadata.co.id/muhammadridhoi/analisisdata/5fb33c772bcf1/memetakan-sektor-potensialekonomi-digital-indonesia (Penulis: Muhammad Ahsan Ridhoi) 